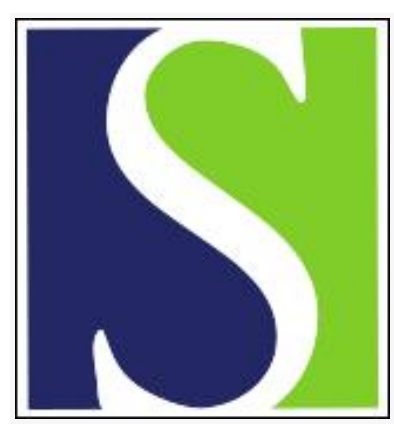

Scand J Work Environ Health 1984;10(6):495-500

https://doi.org/10.5271/sjweh.2295

Issue date: Dec 1984

Work, stress and health.

by Levi L

This article in PubMed: www.ncbi.nlm.nih.gov/pubmed/6535251

\title{
(c) (i)
}




\title{
Work, stress and health
}

\author{
by Lennart Levi, MD
}

\begin{abstract}
LEVI L. Work, stress and health. Scand $J$ Work Environ Health 10 (1984) 495-500. Work should provide a goal, meaning, content, and structure for life and give the worker identity, self-esteem, companions, friends, and material means. If the fit between the worker and the job is bad, if the worker is unable to control his work conditions, if he copes ineffectively and lacks social support, potentially pathogenic reactions occur. These reactions can be cognitive, emotional, behavioral, and physiological. Under some conditions of intensity, frequency and duration, and in the presence or absence of certain interacting variables, these reactions will lead to disease - physical, mental, or both. Research to identify high-risk situations, groups, and reactions for the subsequent interdisciplinary evaluation of therapeutic and/or preventive interventions on a model scale include epidemiologic, observational, and experimental studies, preferably in real life. Examples of such studies are given and additional ones are proposed.
\end{abstract}

Key terms: automation, coping, industrialization, levels for intervention, research strategies, shift work, social support, unemployment.

The organizers of this meeting asked me not just to present a few studies related to the topic of work, stress and health but, instead, to provide a rather broad overview of the entire area, a smorgasbord from which everyone can choose whatever he or she considers useful.

\section{What a good job should provide}

The first question concerns how work conditions and the work environment should be ideally. According to an ILO resolution (3) there are three important requirements for work:

1. It should respect the worker's life and health, a problem of safety and healthiness in the workplace.

2. It should leave the worker free time for rest and leisure, a question of hours of work and their adaptation to an improved pattern for life outside work.

3. It should enable the worker to serve society and achieve self-fulfillment by developing personal capacities, a problem of the content and the organization of work.

The content and organization, I want to consider this point first for a moment. What should a good job provide? According to Marie Jahoda (4) a good

1 Laboratory for Clinical Stress Research/WHO Psychosocial Centre, Karolinska institutet, Stockholm, Sweden.

Reprint request to: Prof L Levi, WHO Psychosocial Centre, Box 60205, S-104 01 Stockholm, Sweden. job has a number of latent functions. (The manifest functions - pay and work conditions - account more often than not for negative feelings about employment.) The latent functions that usually account for positive motivation are (i) the time structure imposed on the working day, (ii) the implication of regularly shared experiences and contacts with people outside the nuclear family, (iii) linkage of individuals to goals and purposes which transcend their own, (iv) the provision of a definition of aspects of personal status and identity, and (v) the enforcement of activity. Or, to put it in other terms, a good job contributes to a goal and a meaning in life, gives the day, week, year, and life content and structure, gives the worker identity and self-respect, as well as an opportunity to give and receive social support, and provides him with money. - This is what a good job should provide. Few jobs do.

\section{Work conditions}

In addition work has changed dramatically in the development from natural, subsistence, and feudal economies to increasingly mechanized and, eventually, computerized modes of production (11). In the natural economy, production was unorganized and was for consumption only. It was a period when mankind survived by hunting wild animals and gathering fruits and roots. Gradually, fishing, settled existence along river valleys, and small-scale agricultural production began. Tribal hierarchies developed and started to recruit, organize, and arm their members to fight nearby tribes. War victims were taken as slaves. The natural economy was gradually replaced by a subsistence economy. The slaves became tenants, and the slave owners the feudal lords. 
Changes in ownership led to larger units, which, in turn, facilitated the introduction of new methods of cultivation. This development yielded more food and, secondarily, a more rapid population growth. The combination of these effects formed a basis for the subsequent process of industrialization (2). This process was characterized by the introduction of complex technological equipment that can be neither owned nor operated by a single person, as well as an extensive division of labor, formal industrial organization, and interdependence between this organization and the wider society.

These changes, characterizing almost two centuries of "industrial revolution" in the developed countries, are now proceeding much more rapidly in the developing countries. In both types of country, the industrialized and the developing, and particularly in the former, there is also a development towards computerization.

Currently all these modes of production exist in different parts of the world, with a rapid and accelerating development towards higher levels of technology.

\section{Health effects}

Needless to say, these and related conditions influence the health and well-being of the worker. The first physician to pay systematic attention to such influences was Bernhardi Ramazzini 284 years ago. In his famous dissertation "De Morbis Artificum Diatriba," he presented the relationship between various occupational conditions on one hand and ill health among the workers on the other. In his preface to one of the subsequent German editions (14) Ramazzini points out that "a medicus visiting common people should not immediately feel the patient's pulse, disregarding his conditions of life, and he should not discuss what is to be done standing up... but sit down for a while, if not on a golden chair, as is the custom in the house of a rich man, but at least on a threelegged stool or bench, and cheerfully ask the patient what is ailing him, how it came about, and how many days it has already been bothering him. Also if he has had evacuation and what he eats. He should also enquire which craft the patient pursues." Ramazzini insisted that this was not only advisable but even necessary. He added that, in the year 1700 , not very many physicians did this - in spite of the fact that, if they would, they would have a key to how to cure the patient.

\section{Models in medical research and clinical practice}

The most famous, and the most commonly applied, model for medical research and clinical practice is the biomedical one. Its instrument is molecular biology. Common variables are changes in organs and in organ functions. Measured are biochemical and physiological processes, and important concepts are atherosclerosis, metabolism, and normality or pathology. Needless to say, this model is indispensable. But it is not sufficient. There is another, not alternative, but complementary model, namely, the psychosocial one. Its instruments are psychology and sociology. Variables are social environment, human experience, and behavior. To be measured are interactions. And important concepts are environmental demands, social networks, and personal resources.

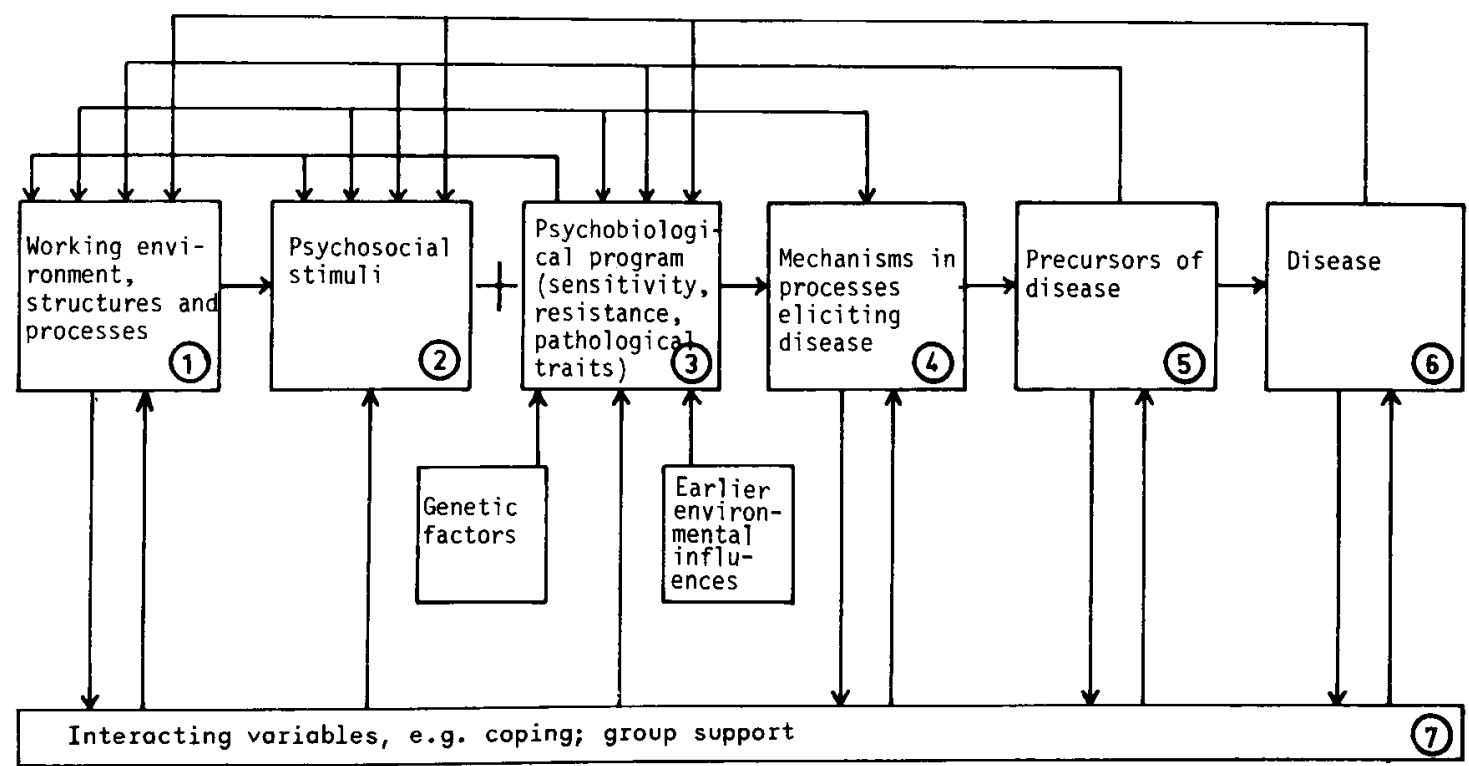

Figure 1. Hypothetical model for work-related "stress" diseases. For an explanation, see the text. 
An optimal approach - both in research and in clinical practice - is to combine the two models. This step is important in medicine, and it is almost by definition equally important in occupational health.

To facilitate an understanding of the interactions in the worker-work ecosystem, a another model is presented in figure 1 . When the fit between work (box 1) and the worker (box 3) is bad, human needs are not being met, the worker finds himself unable to control the conditions he is exposed to, and human abilities are over or under taxed, the organism reacts with various pathogenic mechanisms (box 4). These mechanisms can be cognitive. Examples are restriction of the scope of perception (tunnel vision) and a lowered ability to concentrate, to be creative, and to make decisions, all leading to decreased ability in the worker to respond adequately to, and master, the occupational challenges he is exposed to. The mechanisms can also be emotional. Examples are feelings of anxiety, depression, alienation, mental fatigue, apathy, and hypochondria (7). There are also behavioral mechanisms, as in the case of the abuse of alcohol, tobacco, or drugs; unnecessary risk-taking in work life and in traffic; unprovoked, aggressive, and violent behavior towards fellow human beings or towards oneself (suicidal behavior). Mechanisms can further be physiological. Some of the physiological mechanisms are related to one specific situation, person, or disease. Others are nonspecific, and these Selye has termed "stress"'(6).

In many instances, these changes are transitory (box 5), disappearing with the discontinuation of the stressful exposure. However, in other cases, exposure to potent stressors does not stop after short periods of time but it goes on for weeks, months, or even years. It seems likely that such prolonged exposures may provoke reactions, which in the long run may become disease-provoking (box 6) $(8,9)$.

This flow of events is modified by interacting variables (box 7), such as ways of coping with the job or the availability of social support.

What is needed is knowledge about what is in each "box", about how any two "boxes" relate to each other, and about the dynamics of the entire system. The high-risk situations (box 1), the high-risk groups (box 3), and the high-risk reactions (box 4) should be identified. And this knowledge is required for an understanding of the factors promoting, or protecting against, ill health.

\section{High-risk situations}

Now, which are the high-risk situations, at work and elsewhere? First comes a bad person-environment fit, in terms of human abilities and environmental demands, human needs and environmental opportunities, and human expectations and the situation as perceived. Examples of such a misfit are threats to survival, health, and well-being, to self-esteem, to close attachment with significant others, to the sense of belonging to a valued group, and to personal development and self-realization. A common denominator to all these threats is a lack of personal control. Because, if a person can influence his situation, he can modify the stressors. But if he cannot, then he becomes exposed to them.

A final stressor arises in conflicts between competing roles, eg, at work and in family life.

\section{High-risk groups}

What conditions the outcome is not only what a person is exposed to, but also who that person is, his vulnerability, his propensity to react with high-risk reactions. Different people react differently to the same influence. Genetic vulnerability no doubt is an important conditioning factor.

Another example is propensity for type A behavior. A third example is low self-esteem, and a fourth is low social competence - eg, manifested in "learned helplessness."

Incapacity to unwind is a another example, as are unrealistic goals or being unable to accept what cannot be changed.

\section{High-risk reactions}

Due to the interaction between high-risk situations and high-risk groups, modified by interacting variables, people react. As already mentioned, they react emotionally and/or cognitively and/or behaviorally and/or physiologically. They react partly in accordance with a program that is phylogenetically very old, namely, by the stress reaction pattern. During the stone age, this was an excellent way of reacting because it prepared the organism for fight or flight, for physical activity. Today, in some instances, it may still be an adequate reaction, but more often it is not.

Now, I shall take a closer look at these high-risk, pathogenic mechanisms. A worker, say, is afraid of being laid off, of being "sacked." Or he is exposed to a very monotonous job that must be performed at a high pace, which he cannot influence. He may react emotionally, with anxiety, depression, apathy, hypochondria, fatigue, or with feelings of hopelessness or helplessness. All these are very common reactions, contributing heavily to morbidity and absenteeism. The dividing line between such reactions and disease is a very floating one. In practice, it is often difficult to say when anxiety is a pathogenic mechanism and when it becomes a precursor of disease or even disease itself.

The worker may further exhibit cognitive reactions, say, by restrictions of scope or perception, "tunnel vision." Difficulties to concentrate, disturbed memory function, hesitation in decision making, and lowered creativity are other examples of reactions 
making the worker less able to cope with the vicissitudes of his worklife.

In many cases, the worker also reacts behaviorally, eg, with respect to alcohol, tobacco, or food consumption. It is no disease to smoke 30 cigarettes a day, but, if a worker does that for a long time, he runs a high risk of getting a number of diseases. If he eats, not because he likes the food or because he is hungry, but to calm down, to relax, to unwind, this action may increase his risk to acquire, eg, cardiovascular or even malignant diseases. Or he may be considering suicide, very definitely a matter of life and death. No less so than if he were exposed to mineral dusts or to toxic chemicals.

The most basic physiological reactions involve the central nervous system and the endocrine glands. Together, they influence virtually every cell in the organism, every organ and organ system, eg, producing increased blood pressure, irregular heart rate, muscular tension with subsequent pain in the neck, head, shoulders, etc.

\section{Interacting variables}

All these reactions in workers exposed to occupational stressors are very common and, in many cases, lead to disease or even death, but they need not do so because their effects can be "buffered" by modifying, interacting factors. Much depends not only on what the worker is exposed to but also on how he copes with his exposures.

A second decisive, modifying factor is social support, given by a fellow worker, a good friend, a member of one's family, or by a group of people, a social network.

\section{Precursors and diseases}

If the combination between stressor exposures, vulnerabilities, and lack of protective "buffering" influences is a negative one, a number of diseases may develop - eg, reactive neuroses or physical functional disorders such as dizziness, syncope, muscular pain, dysfunction of the gastrointestinal tract, cardiovascular dysfunction, sexual dysfunction, and others (5).

A third large group includes virtually all physical structural morbidity, in the sense of an emotional overlay, through an influence on health care and other behaviors (eg, tobacco or alcohol abuse) or through the aforementioned physiological mechanisms. If a worker has a broken leg and very much wants to come back to work as early as possible because he loves his job, his recovery will be influenced very differently from when he hates his work and makes use of every excuse not to return to it.

\section{Unemployment}

Thus far, I have summarized the dramatic changes in work life in developing and industrialized countries. Mention should also be made of an environmental factor rarely considered in the occupational environment and health context, namely, the risk of unemployment and actual unemployment or underemployment.

Ten years ago there were 2 million unemployed workers in Western Europe. Five years ago there were 10 million. Today there are 20 million, and there may well be 25 million in 6 years' time. In the $O E C D$ countries there are today 35 million unemployed. Over the next 6 years $18-20$ million new jobs must be created if this figure is not to be increased accordingly. The global situation is that there are some 500 million unemployed or severely underemployed, and this figure might well rise to 1 billion by the year 2000 .

One billion new jobs needed - in a situation where agriculture is becoming increasingly mechanized and industry increasingly computerized. Will the service sector really be able to swallow these enormous amounts of additional people? If the answer is "no," large groups will be denied the benefits of gainful employment, described by Jahoda (4), with consequent possible mental, psychosomatic, and povertyrelated ill effects on a global scale. While hundreds of millions of workers will be facing the problems of unor underemployment, others are exposed to too high a work load. Every seventh adult Swede is mentally exhausted towards the end of the workday. Pronounced mental decompensation occurs before the age of 60 years in every second male and in three women out of four. Alcohol abuse is found in $10 \%$ of all Swedish males. We have 2000 suicides and 20000 suicide attempts annually in a population of 8.3 million. It is likely that a considerable proportion of this morbidity and mortality is job- or unemployment-related.

\section{Research approaches}

Now, how can these problems be approached from the research point of view? To identify health problems and their environmental correlates, epidemiologic studies are used based on aggregate or individual data. Aggregate studies tell that, say, unemployment is increasing on a national scale and that mortality from self-inflicted injury, liver cirrhosis, and myocardial infarction exhibit a corresponding increase, say, two or three years later (1). What is not known is who becomes ill - the persons who became unemployed or those who remain employed but fear unemployment and, in addition, have to work harder because there are fewer laborers left or perhaps the family members of the unemployed or those who are particularly vulnerable. 
Another approach is through retrospective, crosssectional, or prospective studies, with data on an individual level. Such studies indicate statistical relationships between situational and/or individual characteristics on one hand and morbidity or mortality on the other. Many examples of such studies have been presented during this symposium, so there is no need for me to enlarge on that approach.

The next - complementary - approach is an interdisciplinary, longitudinal, intensive one. Say, that there is reason to believe that members of an occupational group are at risk to develop, eg, myocardial infarction. One way to study the likelihood for this possibility is to follow a sample of such a group over time, together with a reference group, in terms of $e x$ posures, as well as pathogenic reactions to these exposures, eg, with regard to those emotional, cognitive, behavioral, and physiological reactions that are known or suspected to be mechanisms in cardiovascular pathogenesis. Such studies provide temporal relationships that may - but need not - be causal in nature.

Next, one can make use of interventions, ie, experiments. Experiments can be performed in a laboratory setting, but also in real life. In the latter case, one can make use of environmental changes that are taking place anyhow (natural experiments). Or one can try to induce environmental and/or behavioral changes that are believed to be beneficial, at least to some people or in some respects or under some circumstances, and evaluate the outcome interdisciplinarily, with a cross-over design. One can, eg, try to improve conditions of work or the work environment, or to modify behavior, say, by making a group comply with safety regulations or stop smoking or abusing alcohol.

\section{Examples of research projects and approaches}

A series of research projects systematically utilizing one after the other of these complementary approaches may clarify what has already been mentioned using the problem area of shift work and health as an example (12). One source of problems in worklife is the temporal misfit between man and his work environment, as can be observed in relation to the altered rest/activity patterns required of subjects with workhours placed outside the conventional daytime range, eg, shift workers.

As a first step in the approach to this problem area, several hundred shift workers were studied with work environment and health questionnaire techniques. The results showed higher frequencies of sleep, mood, digestive, and social disturbances among shift workers than among day workers. Complaints about well-being reached their peak during the night shift.

These studies were complemented by another series in which normal healthy volunteers of both sexes were exposed to three days and three nights of continuous work. In spite of the strict standardization and equalization of environmental stimuli, the circadian rhythms persisted throughout the vigil, pronounced decreases in adrenaline excretion, short falls in performance and increases in fatigue ratings taking place during the early morning hours (6).

In a third step, we studied physiological, psychological, chronobiological, and social reactions in response to the introduction of three weeks of night work to habitual daytime railroad workers. We found that, although the endocrine system does indeed adapt to the environmental demands induced by shift work by "stepping on the gas" to keep the worker awake at night and "slowing down" in the day to allow the worker to sleep, the usual one-week cycle does not suffice for a complete adaptation of turning night into day and vice versa. Not even three weeks of continuous night work are enough to cause an inversion of the circadian functions; the original circadian rhythms flatten out but still persist. In addition, switching from habitual day work to three weeks of night work is accompanied by increases in a number of indices of physiological stress (uric acid, glucose, cholesterol, excretion of adrenaline) and social problems among the workers and their families.

In a logical fourth step, night work was not introduced but instead eliminated. A group of steelworkers was kept on a continuing 3-shift schedule, whereas a comparable experimental group was switched to 2 -shift work, everything else being held constant and equal. In a one year follow-up we were able to demonstrate that the change to work schedules without a night shift brings with it an improvement in physical, mental, and social well-being. The reference group that remained on their habitual 3-shift work schedule did not change, or even deteriorate, with respect to well-being.

In a fifth step we studied police officers who were working habitually in rapidly rotating shifts, with each shift being earlier than the previous one, ie, with a counterclockwise rotation of shifts. In a cross-over design ( $4+4$ weeks), a change to clockwise rotation was introduced and evaluated (based on the assumption that it is easier to lengthen the day than to shorten it). The change to clockwise rotation was found to result in improved sleep and decreases in fatigue ratings, systolic blood pressure, triglycerides, and glucose (13).

Other groups approached with related combinations of research strategies include preschool children, elementary school teachers, industrial workers, unemployed workers, pensioners, and patients with cardiovascular, gastrointestinal, or malignant diseases, always with the general aim to identify highrisk situations, high-risk groups, and high-risk reactions and to propose and evaluate, on a model scale, possible disease-preventing interventions. 


\section{Interventions on seven levels}

Following such evaluation on a model scale, interventions could, and should, be applied, and reevaluated, on one or more of the following seven levels (10):

1. The structural macro level (for example, improved content and organization of work in the entire nation, improved forms of collaboration and employee codetermination) usually through legislation or collective bargaining

2. The structural micro level (for example, an improved work environment in a certain specific factory, office, or enterprise)

3. The level of increasing resistance to illness in individual workers (increased social competence, improved nutrition, training in coping and conflict resolution, etc)

4. The level of adaptation to reality (realistic expectations as to supervisor, fellow workers, work content, salary, etc)

5. The level of getting "the right job for the right person" in a pluralistic society (eg, vocational guidance)

6. The level of crisis intervention and "buffering" social support during critical periods, especially for high-risk groups

7. The level of increasing opportunity, courage, and competence in individual workers to cope with their own and each other's problems

Most important is to integrate the planning and execution of measures for promoting occupational health and preventing work-related and other diseases (and hence improving the quality of life) on all these levels. To decide on such measures on structural levels is a task for politicians, management, and labor unions. However, individual workers and groups of employees can and should, to varying degrees, also make an important and sometimes decisive contribution.

Among those interventions for which preliminary evidence suggests the value of additional research are (12): (i) increasing a worker's control of the work arrangements, (ii) providing mechanisms for worker participation in decision making on the organization of work, (iii) avoiding monotonous, machine-paced, and short but frequent work actions, (iv) optimizing automation, (v) helping workers see their specific task in relation to the total product, (vi) avoiding quantitative work over- or underload, and (vii) facilitating communication and support systems among workmates and others.

As more information about these and other interventions becomes available, it should be possible to begin to explore difficult but critical issues about the balance between social needs for productivity and individual requirements for good physical and mental health. The evidence already available suggests that, in some instances, adequate understanding of the stressful aspects of a work setting may make it possible actually to improve both.

\section{References}

1. Brenner MH. Impact of social and industrial changes on psychopathology: A view of stress from the standpoint of macro societal trends. In: Levi L, ed. Society, stress and disease. Volume 4. Oxford University Press, Oxford, New York, Toronto 1981, pp 249-260.

2. Carlestam G, Levi L. Urban conglomerates as psychosocial human stressors. Royal Ministry for Foreign Affairs, Stockholm 1971.

3. International Labour Organisation. Conclusions concerning future action in the field of working conditions and environment: International Labour Conference, 70th Session. Geneva 1984.

4. Jahoda M. The impact of unemployment in the 1930 s and the 1970s. Bull Br Psychol Soc 32 (1979) 309-314.

5. Levi L, ed. Society, stress and disease - The psychosocial environment and psychosomatic diseases. Oxford University Press, London, New York, Toronto 1971.

6. Levi L. Stress and distress in response to psychosocial stimuli. Acta Med Scand Suppl 528 (1972) 166 p.

7. Levi L, ed. Emotions - Their parameters and measurement. Raven, New York, NY 1975.

8. Levi L. Society, stress and disease - Working life. Oxford University Press, Oxford, New York, Toronto 1981.

9. Levi L. Preventing work stress. Addison-Wesley, Reading, MA 1981.

10. Levi L. Stress in industry. International Labour Office, Geneva 1984.

11. Levi L. Occupational psychiatry - Concepts, models' problems and objectives. Paper presented at the WPA Section Symposium on Occupational Psychiatry. Proceedings of the 7 th World Congress of Psychiatry. Plenum, New York, NY 1984.

12. Levi L, Frankenhaeuser M, Gardell B. Work stress related to social structures and processes. In: Elliott GR, Eisdorfer C, ed. Research on stress and human health. Springer, New York, NY 1982, pp 95-117.

13. Orth-Gomér K. Interventions on coronary risk factors by changing working conditions of Swedish policemen. Acta Nerv Super (Praha) (1982): suppl 3, 223-229.

14. Ramazzini B. Undersuchung von den Krankenheiten der Künstler und Handwerker. Weidmann, Leipzig 1718 . 